\title{
The effects of smoking in developing hypertension in Pakistan: a systematic review
}

\author{
Qurrat ul Ain ${ }^{1}$, Krishna Regmi ${ }^{2}$ \\ ${ }^{1} \mathrm{PhD}$ Research Scholar, Centre for Research in Primary and Community Care, University of Hertfordshire, UK. \\ ${ }^{2}$ Principal Lecturer in Public Health, Faculty of Health and Social Sciences, Institute for Health Research, University of \\ Bedfordshire, UK.
}

\begin{abstract}
Globally, hypertension is considered one of the most important preventable causes of morbidity and mortality. Several plausible factors have been assessed and identified in relation to high blood pressure but there have been limited studies carried out as to whether smoking can have any effect in developing high blood pressure in Pakistan. This paper aims to examine the effects of smoking in developing hypertension in Pakistan. This study employs a systematic review. A total of 1097 articles were identified (reduced to 61 once duplication was removed). Only six studies met the relevant quality appraisal criteria. Three major databases - Medline, EMBASE and Global Health were searched using both 'free terms' and 'index-terms'. All selected studies were quality appraised by critical appraisal tools and reviewed by two authors. The studies fell into three distinct themes - awareness, economic status and types of tobacco. Findings of the review indicated that an unhealthy relationship exists between hypertension and smoking, as incidences of hypertension were more prevalent in smokers as compared to non-smokers. In addition, both high systolic and diastolic blood pressure were more frequent in smokers compared to non-smokers. The present study suggests that a positive harmful relationship exists between blood pressure and smoking, and that smokers are more likely to develop high blood pressure compared to non-smokers. In addition, this review considers knowledge and lifestyle modification, their linkage with hypertension and compliance to the treatment regimen as important considerations to reduce unhealthy effects of smoking in developing hypertension.
\end{abstract}

Keywords: Hypertension, High blood pressure, Smoking, Tobacco, Pakistan.

\section{Introduction}

Hypertension (HTN) is a global public health problem. It is one of the most valuable preventable causes of premature morbidity and mortality in the world and its management is one of the most common interventions in primary care. HTN affects over $26 \%$ of the adult population worldwide. ${ }^{1}$ Although smoking is considered one of main risk factors of hypertension, ${ }^{1-3}$ smoking with high and low nicotine cigarettes are particularly responsible for an increase in high systolic blood pressure, heart rate and myocardial oxygen demand. The World Health Organisation (WHO) ${ }^{4}$ estimated that there will be over 20 million cardiovascular deaths in 2015 , which will account for $30 \%$ of deaths worldwide. HTN has earned the reputation as the 'silent killer' making it a key priority for prevention, detection and control. High blood pressure is a major risk factor for strokes, heart failure, chronic kidney disease, coronary artery disease and cognitive decline that is ultimately responsible for causing over $60 \%$ of deaths in developed countries and $80 \%$ in developing countries, including Pakistan. ${ }^{5,6}$

The $\mathrm{WHO}^{5}$ further reports that cardiovascular diseases alone killed 2 million people in 2011 in low- and middleincome countries. Morbidity associated with complications of hypertension account for 9.4 million deaths worldwide every year. Although hypertension can occur at any age, it is more common amongst adults due

\section{Practice Points}

- Hypertension is a global public health problem.

- Smoking is considered one of main risk factors of hypertension, and smoking with high or low nicotine cigarettes are particularly responsible for an increase in high systolic blood pressure, heart rate and myocardial oxygen demand.

- People in Pakistan often use tobacco products because of their affordability and because of a widely held misconception that there use could be beneficial in easing stomach aches, toothaches and headaches.

- Tobacco products and hypertension appear independent of age, sex and area of residence.

- Awareness does modify health behaviour and the findings of this review support the idea that better informed hypertensive subjects were less likely to be involved in smoking habits.

to involvement in unhealthy behaviours and lifestyles. Smoking causes an acute increase in blood pressure; heart rate has been associated with malignant hypertension that causes a sudden rise in very high blood pressure. ${ }^{8}$ Nicotine chemicals in tobacco act as

Correspondence: Dr Krishna Regmi, Faculty of Health and Social Sciences, Institute for Health Research, University of Bedfordshire, Putteridge Campus, Luton LU2 8LE, UK. Email: krishna.regmi@beds.ac.uk. 
an adrenergic against local and systematic catecholamines, and mainly vasopressin, to increase pulse rate, followed by heart rate and blood pressure simultaneously. ${ }^{7,9}$ The prothrombotic effect of continuous tobacco exposure causes alterations in blood cells, platelet function, antithrombotic and fibrinolytic factors. ${ }^{7,9,10}$

Several studies have shown that there is an alteration in blood pressure and heart rate associated with those who have stopped smoking tobacco. ${ }^{7-9}$ Any amount of smoking, even occasional, damages the heart and blood vessels, and chemicals in smoke form plaques within the arteries. ${ }^{1}$ Acute exposure to passive (environmental) smoking determines a gradual increase in blood pressure due to the combined effect of nicotine that acts by endothelial dysfunction and sympathetic stimulation. Moreover, carbon monoxide in tobacco smoke exerts its toxic effect directly. ${ }^{11}$ It is interesting to note that prevalence of smoking has been reported at 38\% amongst 32 East Asian countries ${ }^{12}$ and $14-21 \%$ in adolescents and adults, and is more common in Pakistan. ${ }^{13}$ People in Pakistan often use tobacco products because of their affordability and because of a widely held misconception that the use of tobacco products could be beneficial in easing stomach aches, toothaches and headaches. ${ }^{14}$ The other reason for this high prevalence is that there is limited evidence and knowledge on smoking hazards in Pakistan, such as its effect on health and lifestyle modification in the general population. ${ }^{15}$

This study therefore aims to evaluate the role and use of smoking in the hypertensive population of Pakistan and to examine the effects of smoking in developing hypertension.

\section{Materials and Methods}

This study utilised a systematic review style - an approach which is considered a legitimate research methodology. Boland et al. ${ }^{16}$ argued that it is a valuable form of research in terms of locating and appraising, as well as synthesising the best available evidence relating to a specific research question to provide 'informative and evidence-based' answers. This approach is generally considered to be of a good standard as it aids in 'synthesising the findings of several studies investigating the same questions ${ }^{16}$, thereby using high quality evidence to inform policy into decision mak- ing. ${ }^{17}$ The Institute of Medicine, ${ }^{18}$ however, warns that it may equally lead to incorrect conclusions, and ultimately wrong decisions or recommendations if we 'fail to acknowledge or address the risk of reporting biases, neglect to appraise the quality of individual studies included in the review, and are subject to errors during the data extraction and analysis.'

\section{Search Strategy}

To identify and highlight the primary research studies and to determine the relationship between hypertension and smoking in Pakistan, the three major electronic databases (MEDLINE, EMBASE, and CABI's Global Health) were searched focusing on smoking and hypertension in developing (low- and middle-income) countries in general and in Pakistan specifically. These databases were considered the best known with international coverage for over 80 countries and about 15000 journals indexed, alongside the vast resources capturing the fields of medicine, international health and related disciplines.

Following the formulation of research questions, a research strategy was planned. An inclusion and exclusion criteria was set, and both free terms (text words) and index-terms (thesauruses) were established, identified and searched from research topics and relevant databases. These criteria stem from the PICO (population, intervention, context/comparison and outcome) framework, defining the participants and the types of interventions to be studied and potentially also limiting the type of study design. ${ }^{19}$ The search tool of these databases identified a total of 61 articles that passed the title and abstract screening. To form a search question, we broke down the search into two major

Table 1: Search terms used

\begin{tabular}{|l|l|}
\hline \multicolumn{1}{|c|}{ Concept 1 } & \multicolumn{1}{c|}{ Concept 2 } \\
\hline Smoking & Hypertension \\
\hline Tobacco & High blood pressure \\
\hline Cannabis smoking & Blood pressure \\
\hline Cigar & \\
\hline Cigarette & \\
\hline Hashish & \\
\hline Hookah & \\
\hline Pipe & \\
\hline Waterpipe & \\
\hline
\end{tabular}

Note: All concepts combined with AND

Table 2: Search terms using PICO

\begin{tabular}{|l|l|l|l|l|}
\hline Population & Intervention/setting & Comparatives/Issues & Context & Outcome \\
\hline Human & Smoking control & Hypertension & Developing country* & Control high BP \\
\hline Men & Smoking cessation & High BP & Low \& middle-income country* & Reduce high BP \\
\hline Women & Hospitals & BP & Asia & Normal BP \\
\hline Gender & Primary healthcare & & Pakistan & \\
\hline Adults & & & \\
\hline Limits & $\begin{array}{l}\text { Population: Human } \\
\text { Language: } \text { English language } \\
\text { Nature: Articles published in peer-review journals } \\
\text { Date: } 1990-\text { 2014 } \\
\text { Context/setting: Developing countries - Pakistan }\end{array}$ \\
\hline
\end{tabular}

Note: $\mathrm{BP}=$ Blood pressure 
concepts (Table 1) and decided upon synonyms for adopting the 'PICO' framework (Table 2).

\section{Results}

Of a total of 1097 papers identified (985 through the database and 112 from other sources), 989 met the relevant criteria. Full-text security of 61 papers was undertaken and six of these were identified for review. The selected papers were categorised according to timing, geographical location, scope and basic features, age and range/types of smoking included (Table 3), following which they were critically appraised using the CASP tool ${ }^{20}$ and reviewed by two authors (Tables 4,5 ). In terms of the process, authors undertook two phases. First, titles and abstracts were screened independently by two authors to identify those studies likely to meet the inclusion criteria. Secondly, authors undertook a full text scrutiny. ${ }^{21}$ The PRISMA flow diagram ${ }^{22}$ was followed to present clear guidance on how the final six studies were identified and screened (Fig 1).

Due to the nature of the topic, research was heterogeneous where achieving overall synthesis of results was inappropriate, therefore authors utilised qualitative synthesis, employing a framework analysis approach to draw descriptive and/or explanatory conclusions clustered around themes. Based on the analysis of the included papers, three themes emerged from this study - lack of awareness, socio economic status, and types of tobacco products.

Table 3: Key characteristics of the six studies selected for inclusion in the review

\begin{tabular}{|c|c|}
\hline Characteristics & Selected studies \\
\hline \multicolumn{2}{|l|}{ Year of study } \\
\hline $1990-2000$ & $1(17 \%)$ \\
\hline $2000-2014$ & $5(83 \%)$ \\
\hline \multicolumn{2}{|l|}{ Location of study } \\
\hline Urban & $5(83 \%)$ \\
\hline Rural/both & $3(50 \%)$ \\
\hline \multicolumn{2}{|l|}{ Sample size } \\
\hline $0-500$ & $4(67 \%)$ \\
\hline $500-4000$ & $2(33 \%)$ \\
\hline \multicolumn{2}{|l|}{ Type of smoking } \\
\hline Tobacco & $5(83 \%)$ \\
\hline Water pipe smoking & $2(33 \%)$ \\
\hline Tobacco chewer & $2(33 \%)$ \\
\hline \multicolumn{2}{|c|}{ Population characteristics } \\
\hline Adults & $3(50 \%)$ \\
\hline Elderly & $3(50 \%)$ \\
\hline Male & $4(67 \%)$ \\
\hline Female & $42(33 \%)$ \\
\hline
\end{tabular}

Table 4: Thematic overview of study findings

\begin{tabular}{|c|c|}
\hline Study & Findings \\
\hline \multicolumn{2}{|c|}{ Lack of awareness $(n=3)$} \\
\hline Saleheen et al. $^{25}$ & $\begin{array}{l}\text { Good knowledge identified as a risk factor is associated with better improvement in health outcomes } \\
\text { Individual habits are influenced by their knowledge and attitude towards these behaviours } \\
\text { Lack of appropriate health education has been linked with lack of therapeutic control in hypertensive } \\
\text { patients } \\
\text { People with hypertension necessitate the development of national education campaigns to increase the } \\
\text { awareness on healthy lifestyle } \\
\text { Improved knowledge and change in health attitude will bring significant decline in rates of } \\
\text { hypertension and smoking }\end{array}$ \\
\hline${\text { Tassaduqe } \text { et } a l . .^{27}}^{7}$ & $\begin{array}{l}\text { Despite less knowledge on lifestyle modification, the Pakistani population has improved their } \\
\text { knowledge level with health education }\end{array}$ \\
\hline Mahesar et al. ${ }^{24}$ & $\begin{array}{l}\text { Education and counselling by physicians has helped in developing effective strategies to deal against } \\
\text { cardiovascular burden }\end{array}$ \\
\hline \multicolumn{2}{|c|}{ Socio economic status $(n=3)$} \\
\hline Khan \& Thaver $^{23}$ & $\begin{array}{l}\text { Socio economic disadvantage has a relationship with poor health and chronic illness } \\
\text { Education and social status captured as an important dimension to make healthy choices } \\
\text { Socio economic position and positive family history of smoking reported to increase in risk of } \\
\text { cardiovascular burden } \\
\text { Individual behaviour correlates with socio economic status (e.g. cigarette smoking) } \\
\text { Smoking and hypertension are related to poor-low socio economic groups or having an adverse lifestyle }\end{array}$ \\
\hline Qamar et al. ${ }^{14}$ & $\begin{array}{l}\text { People among poor and middle socio economic groups smoke all types of tobacco products frequently } \\
\text { due to lack of knowledge on smoking hazards } \\
\text { Positive family history of smoking has associations with enhanced addiction of tobacco and more risk } \\
\text { of cardiovascular damage } \\
\text { Social group hypertension rate has appeared as common due to the usage of tobacco products }\end{array}$ \\
\hline Tassaduqe et $a l . .^{27}$ & $\begin{array}{l}\text { Relationship between smoking, hypertension and social status are linked } \\
\text { More research is needed to explore these parameters } \\
\text { Individual behaviour is linked with control and prevention of hypertension }\end{array}$ \\
\hline \multicolumn{2}{|c|}{ Types of tobacco products $(n=1)$} \\
\hline Shafique et al. ${ }^{26}$ & $\begin{array}{l}\text { Regardless of socio economic status, people are more prone towards alternative forms of tobacco } \\
\text { products such as water pipe tobacco } \\
\text { Flavouring of tobacco and charcoal has not appeared as alternatives to reduce harmful effects of } \\
\text { smoking } \\
\text { All tobacco products are related to high blood pressure in all age groups }\end{array}$ \\
\hline
\end{tabular}




\begin{tabular}{|c|c|c|c|c|c|c|}
\hline & 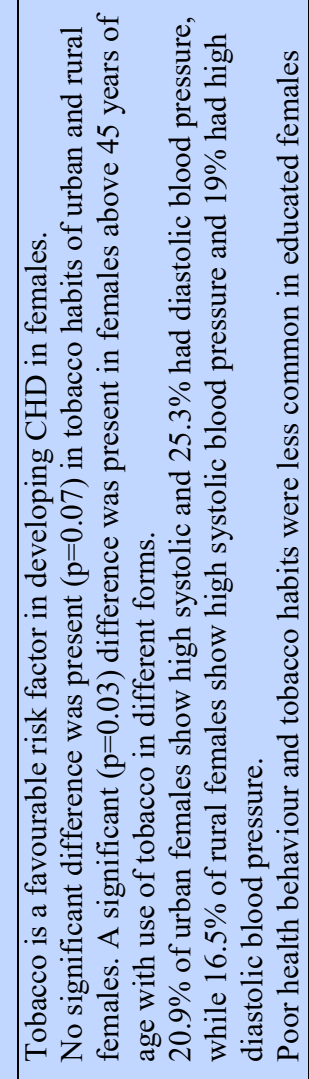 & 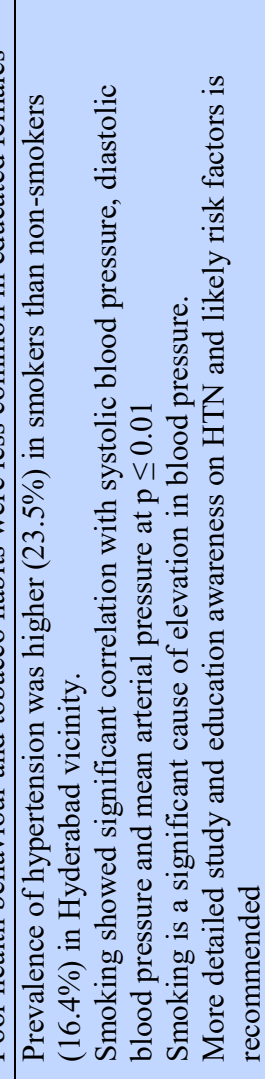 & 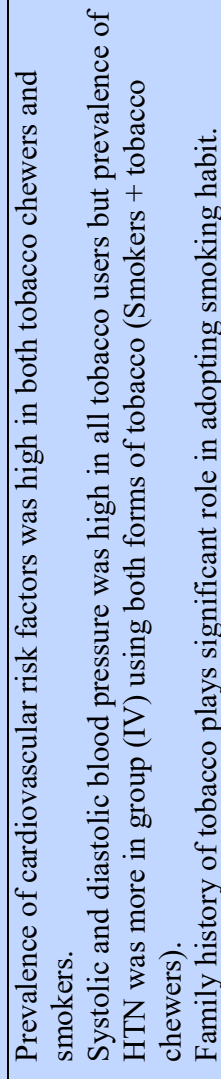 & 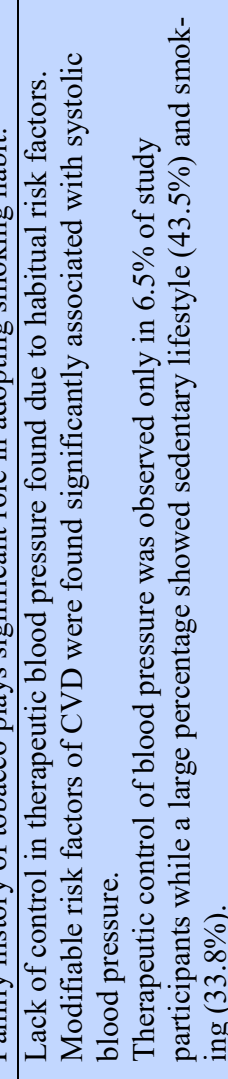 & 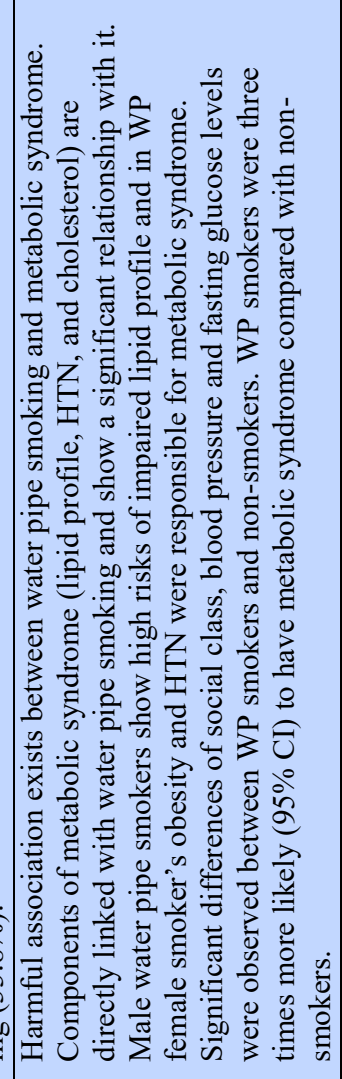 & 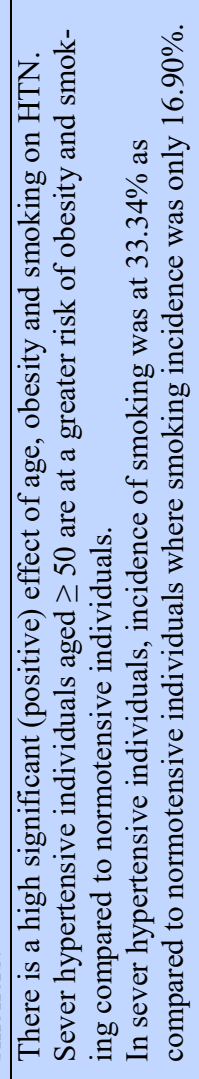 \\
\hline 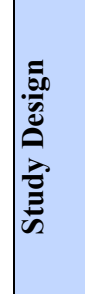 & 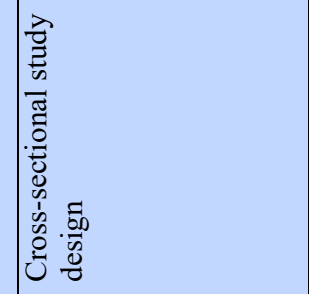 & 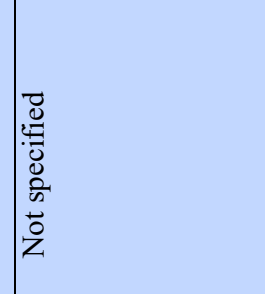 & 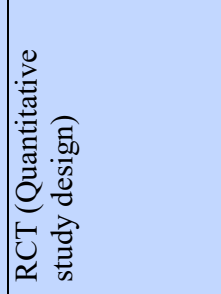 & 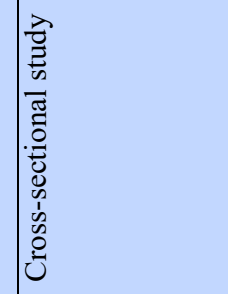 & 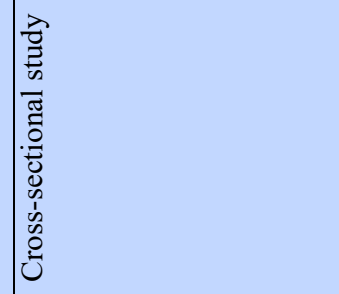 & 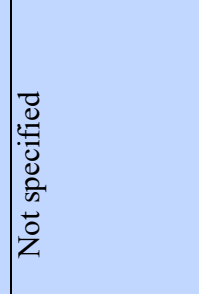 \\
\hline & 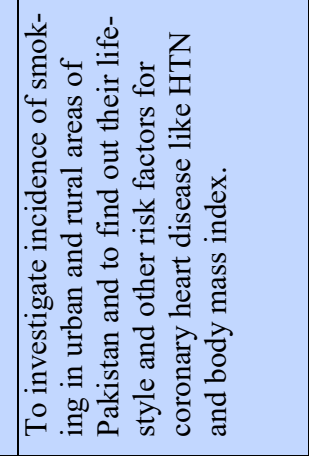 & 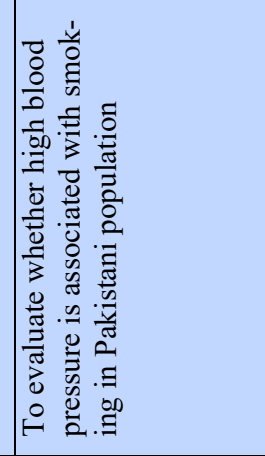 & 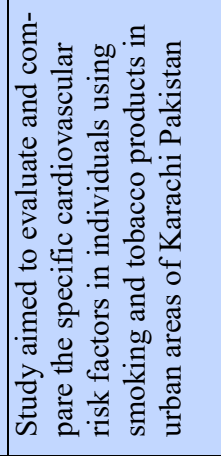 & 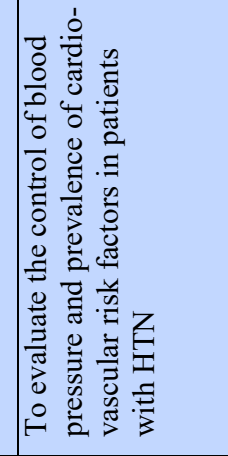 &  & 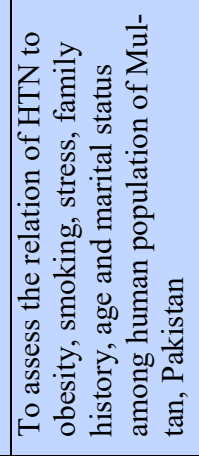 \\
\hline 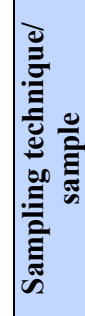 & 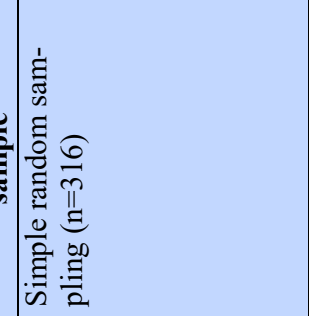 & 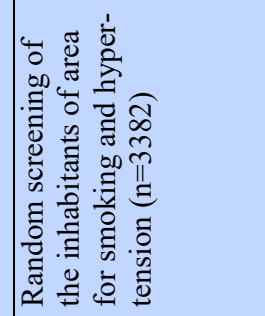 &  & 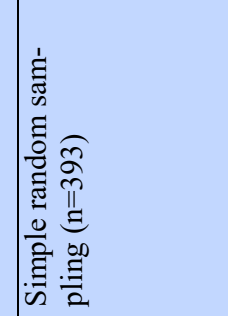 & 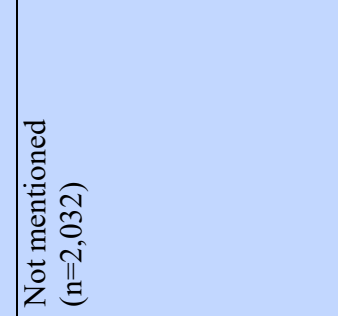 & 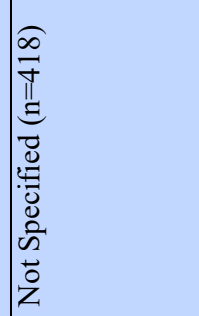 \\
\hline 莣 & 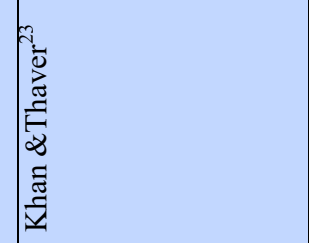 & 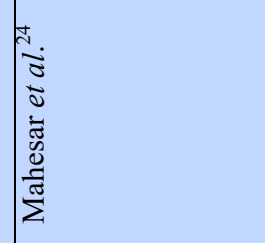 & 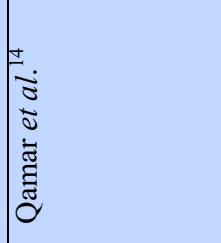 & 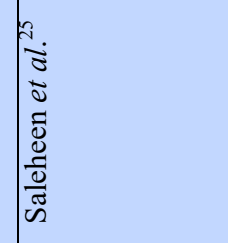 & 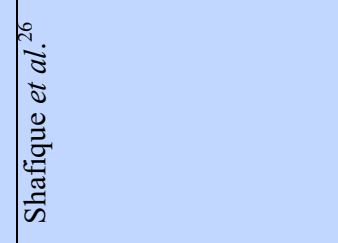 & 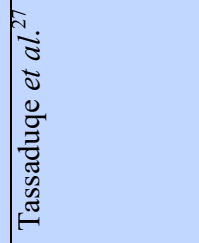 \\
\hline
\end{tabular}




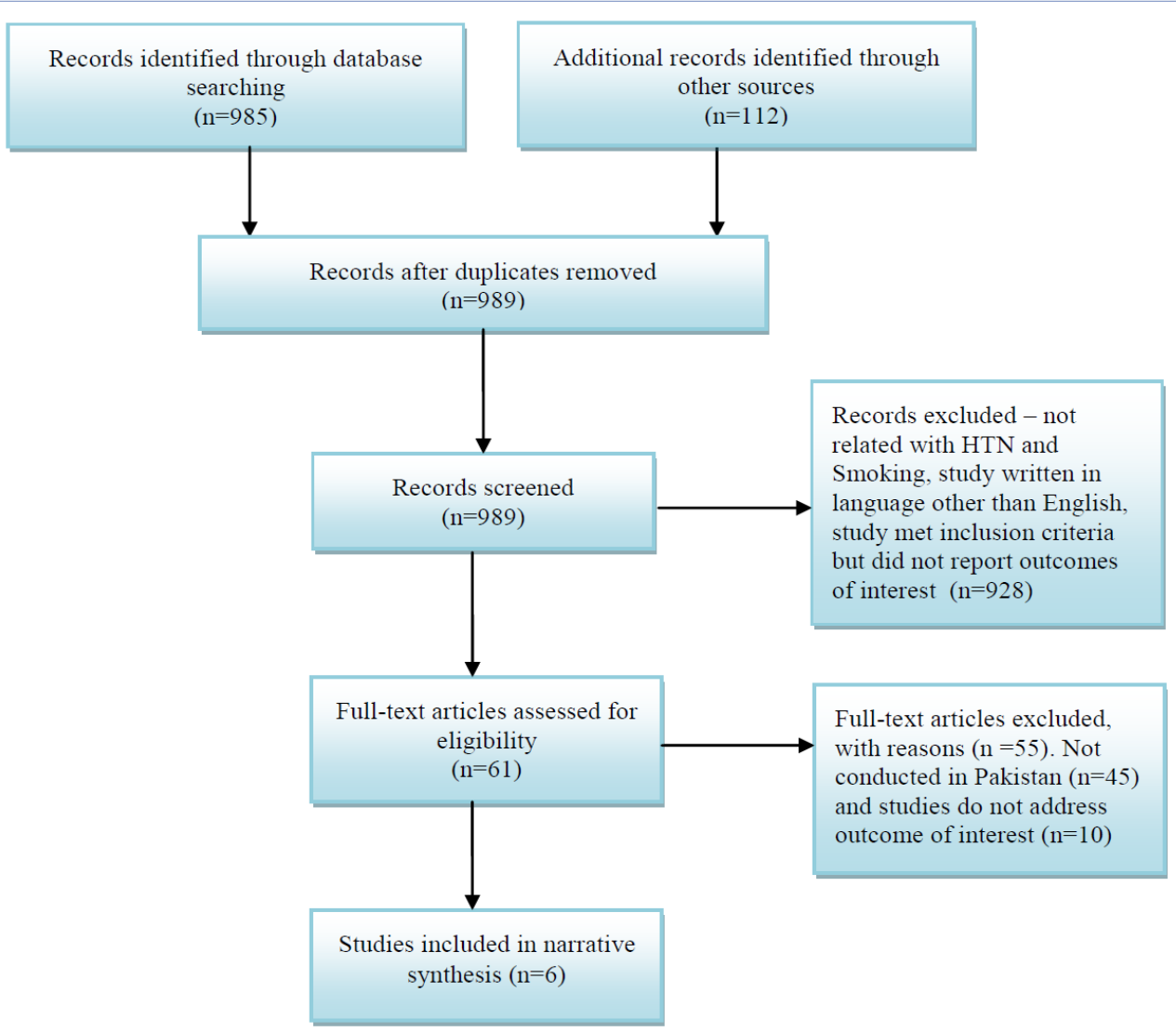

Figure 1: Flowchart of the process of identifying included studies

\section{Lack of awareness}

Lack of awareness was one of the core themes that emerged from this review. Patients were not aware of the diagnosis of hypertension and its relation with lifestyle modifications associated with this chronic disease. $^{24,25,27}$ Therefore, it is understandable that incidences of cardiovascular burden and smoking is rising in Pakistan. Findings further revealed that hypertensive patients either did not have enough information about the risk factors associated with high blood pressure nor had access to effective blood pressure control strategies adopted by Pakistani health physicians. Most of Pakistan's population possess poor information about cigarette hazards and so are less likely to cite smoking as a health risk. Awareness does modify health behaviour and the findings of this review support the idea that better informed hypertensive subjects were less likely to be involved in smoking habits.

\section{Socio-economic status}

The theme of socio economic status was a prominent determinant towards smoking in all selected studies. There is a strong linkage between tobacco use and socio -economic status. The use of all tobacco products was more prevalent among people of low and middle-class socio economic statuses in Pakistan. ${ }^{14,23,27}$ People with a low socio economic status are less likely to get into secondary education. Despite differences of educational levels in different socio-economic classes, the ignorant and those belonging to a low socio-economic status are more likely to have much difficulty in pursuing anti-smoking measures. $^{2}$

\section{Type of tobacco products}

It has become apparent from selected studies that all kinds of tobacco (smokeless, water pipe and chew) are commonly used in Pakistan. ${ }^{26}$ The observed relationship between tobacco products and HTN is independent of age, sex and area of residence. Similar toxicants present in all tobacco products bring about an increase in blood pressure by causing vasoconstriction within blood vessels. Despite that, people are unable to identify the risk associated with each tobacco product. However, it is unknown as to what extent each separate tobacco product affects the blood pressure in hypertensive individuals.

\section{Methodological characteristics}

The overall methodological quality of the included studies was reasonably poor. Two papers ${ }^{14,26}$ of the six reported sufficient information provided about the methods and procedures. Only one paper ${ }^{24}$ exclusively focused on the effects of smoking on blood pressure and showed significant correlation of raised blood pressure in smokers as compared to non-smokers in the male and female population. One paper ${ }^{24}$ had a larger sample size compared to the other five selected studies, however, this was still restricted to one city in Pakistan. Out of the six papers ${ }^{14,23-26,27}$ only one study recommended the need for a 'smoking cessation programme in order to prevent high rates of non-communicable diseases in the country'. With the exception of two papers ${ }^{24,27}$ four others addressed sufficient details on ethical issues. Except one, all studies were carried out between 2004 and 2012, and they were consistence in terms of similar 
or higher rates of smoking among the Pakistani population.

\section{Discussion}

The review demonstrates emphasis on the relationship between smoking and HTN in Pakistan by answering the research question: does smoking have an influence in regards to increased blood pressure in the population of Pakistan? The results reveal that smoking causes harmful effects in developing HTN and is a potential susceptible factor for high blood pressure. The findings of this study are consistent in terms of the fact that smoking is a risk factor in regards to increased blood pressure. In addition, the results show that the occurrence of smoking appeared among severe hypertensive individuals, and caused a greater number of hypertensive patients. ${ }^{27}$ Despite these findings, overwhelming evidence supports the idea that cigarette smoking causes various adverse cardiovascular events. ${ }^{7}$ This review explores the suggestion that smoking significantly increases blood pressure and smokers are more likely to have high blood pressure than non-smokers and ex-smokers. ${ }^{14,23-}$ 27

Khan and Thaver ${ }^{23}$, and Mahesar et al. ${ }^{24}$, for example, showed statistically a notable variation in blood pressure level among different kind of smokers (see Table 5). To support the positive (harmful) relationship between smoking and HTN, some theories have been evaluated in a laboratory setting, such as the study that found a new substance - one of the nicotine metabolites - named cotinine that relaxes vascular smooth muscles and dilates blood vessels in smokers. ${ }^{28}$ However, these results contrast the findings of some studies that support a causal relationship between chronic smoking and reduction in high blood pressure. $^{29,30}$

The observed negative relationship between smoking and blood pressure would probably attribute to nicotine metabolites. All kinds of tobacco (chew form, water pipe and smokeless) cause significant increases in blood pressure among the male and female population. ${ }^{14}$ This supports the idea that smoking can cause a variation in blood pressure, however, it is unknown to what proportion each separate outcome affected the results. To date, the results of this show that the effect of smoking on blood pressure is related to other predictors such as education and social status in Pakistan. ${ }^{27}$ The social and education status of females was a major determinant in adopting smoking habits in Pakistani females. ${ }^{23}$ Our review suggests that knowledge about HTN is not only necessary among patients, but should also be conveyed to the general population due to fact that, in Pakistan, family members play a vital role in patient care.

A recent study conducted in Pakistan found that knowledge of HTN was better in the middle-socio economic class compared to the lower income class and attributed this disparity to education level and awareness. However, this claim was opposed by another study where water pipe smoking and high blood pressure were statically significant in professional groups. ${ }^{26}$ It was very reassuring to see that in one study many of the participants (393) were aware of high blood pressure. However, control and awareness regarding HTN was at only $6.4 \% .{ }^{25}$ Poor compliance appeared more common amongst people who had poor or limited knowledge, understanding and perception of their disease and treatment. ${ }^{30}$ Nonmodifiable risk factors such as age, ethnicity and gender have more links with HTN rather than modifiable ones. ${ }^{3}$

Although some studies have reported that no association exists between smoking habits and blood pressure, ${ }^{31,32}$ each cigarette induces a similar and statically significant increase in both blood pressure and heart rate which lasts for a long time. ${ }^{33}$ This is further demonstrated by the positive effect of smoking on blood pressure and also by analysing the amount of nicotine in cigarettes statically - proving that there were significant increases in systolic and diastolic blood pressure in smokers. ${ }^{33,34}$ While the problem of heterogeneity appeared in the included studies, research makes it difficult to synthesise the findings, although it is possible to identify issues for further research. Control of HTN has become of the utmost importance in Pakistan as the incidence of cardiovascular complications is rising sharply in this region. $^{35}$

A major strength of this systematic review is the comprehensiveness of the search strategy. To gain all available literature, and to answer the research question, extensive database searches were accomplished by hand. There was no published systematic review which briefly examined the relationship of smoking and HTN in the population of Pakistan. The quality of data extraction, analysis of literature and unbiased reporting of its findings increased the quality of this review. Though this study has addressed some important aspects of smoking and HTN in the context of Pakistan, some aspects have not been covered due to the minimum time period and resource constraints.

Application of the inclusion criteria identified six papers for inclusion in this review, a surprisingly small number given the nature of the topic. Nonetheless, the use of a thorough process of search strategies (concepts and PICO framework) and supplementation of the results of the electronic search - with a handheld searching of reference lists of included papers have allowed for some degree of confidence in terms of drawing conclusions from the available evidence within the study context. This review is based on the Pakistani population; therefore findings of the present study may be difficult to compare or generalise. This includes outcomes across all hypertensive patients in other parts of the world due to the distribution of cardio-metabolic risk factors and conditions that significantly vary between different population groups. Similarly, few paper provided limited descriptive 
statistics e.g. prevalence of hypertension in smokers vs. non-smokers ${ }^{1-3}$ and some attempted to compare tobacco use between urban and rural females ${ }^{1}$. Others revealed population characteristics that showed a higher prevalence of smoking in those with hypertension ${ }^{4-6}$ but none of them sufficiently examined the association between smoking and hypertension.

\section{Conclusion and recommendations}

This study highlighted that the knowledge and lifestyle modification, their linkage with hypertension and compliance to the treatment regimen are important considerations in reducing the unhealthy effect of smoking in developing hypertension. The review revealed the harmful relationship between blood pressure and smoking, and that smokers appeared more likely to develop high blood pressure in comparison with non-smokers, although no analysis tool was used to confirm degrees of harmful relationships between two variables due to heterogeneity among six selected studies. Different methodology designs used in selected studies may lead to differences in observed effects however, and results of this review conclude that there is a convincing association between HTN and smoking through extensive data search. Our study emphasises that there is a need for additional evidence - considering both the methodological and conceptual limitations are required for providing evidence based support linking smoking to hypertension.

Results from the review found that preventive approaches to chronic disease is based on modifiable risk factors such as tobacco, salt intake and obesity, and appropriate knowledge and awareness in practice. Hypertension is considered a chronic disease - hence its prevention needs to control the most common and modifiable risk factor, i.e. smoking. The study strongly recommends that, to identify the hypertension associated risk factor, the knowledge and awareness programme needs to be suggested at both local and national health levels, in partnership with different governments, non-governments and external development partners to prevent or minimise the potential adverse effects that can be caused by smoking. In addition, there is a dire need for aggressive anti-smoking awareness campaigns in Pakistan. We would strongly recommend that the government, taking the initiative from Pakistan's Ministry of Health and similar geo-political institutions in the south-east regions, should implement new, or re-enforce existing, anti-smoking laws - for example, prohibiting smoking in public places.

\section{Competing interest}

The authors declare that they have no competing interests.

\section{Authors' contributions}

QA conceived and designed the study with the advice from KR; QA and KR reviewed, analysed and interpreted the data and contributed to drafting and finalising the manuscript.

\section{Acknowledgement}

This article is based on research undertaken for a public health project at the University of Bedfordshire, UK. The authors would like to thank those seven unanimous reviewers who provided their useful comments in the preparation of this study.

\section{References}

1. Abtahi F, Kianpour Z, Zibaeenzhad MJ, Naghshzan A. Heydari ST. Beigi MA, Khosropanah SH, Moaref, AR, Zamirian, M. Correlation between cigarette smoking and blood pressure and pulse pressure among teachers residing in Shiraz, Southern Iran. Iran Cardiovasc Res $J$ 2011;5:97-102.

2. Agrawal LT, Bhalwar Col, Bassannar. Prevalence and determinants of hypertension in rural community. Med J Armed Forces India 2008; 64:21-5.

3. Doch,i M, Sakata, K, Oishi, M, Tanaka, K, Kobayashi, E, Suwazono,Y. Smoking as independent risk factor for hypertension: A 14 year longitudinal study in male Japanese workers. Tohoku J Exp Med 2009;217:37-43.

4. World Health Organization. Preventing chronic diseases a vital investment: WHO Global Report. Geneva: World Health Organization, 2008.

5. World Health Organization. Cardiovascular diseases. http://www.who.int/mediacentre/ factsheets/fs317/en/ (accessed June 2015)

6. Glasziou P, Irwig L, Bain C, Colditz G. Systematic reviews in health care: A practical guide United Kingdom: Cambridge University Press, 2001

7. Ahmad K, Jafary F, Jehan I, Hatcher, J, Khan AQ, Chatuvedi N, Jafar TH. Prevalence and predators of smoking in Pakistan: results of National Health Survey of Pakistan. Eur J Cardiovasc Prev Rehabil 2005;12:203-08.

8. Primatesha P, Falaschetti E, Gupta S, Marmot M, Poulter N. Association between smoking and blood pressure: Evidence from health survey for England. Hypertension 2001;37:18793.

9. Cryer PE, Haymond MW, Santiago TV, Shah SD. Norepinehrine and epinephrine release and adrenergic mediation of smoking-associated hemodynamic and metabolic events. $N$ Engl $J$ Med 1976;295:573-77.

10. Ambrose JA, Barua RS. The pathophysology of cigarette smoking and cardiovascular disease: an update. J Am Coll Cardiol 2004;43:1731-37.

11. Kato T, Inoue T, Morooka T, Yoshim N, Node $\mathrm{K}$. Short term passive smoking causing 
endothelial dysfunction via oxidative stress in non-smokers. Can J Physiol Pharmacol 2006;84: 523-29.

12. Jha P, Ranson MK, Nguyen SN, Yach D. Estimates of Global and Regional Smoking Prevalence in 1995, by Age and Sex. Am J Public Health 2002;92:1002-6.

13. Alam SA. Prevalence and pattern of smoking. $J$ Pak Med Assoc 1988;48:64-6.

14. Qamar A, Ni Khan, L Naz, G. Assessment and comparison of cardiovascular risk factors among smokers and tobacco chewers. Int J Biol Biotechnol 2008; 5:219-24.

15. Zafar NA, Gowani SA, Irani FA, Ishaq M. Awareness of risk factors, presenting features and complications of hypertension amongst hypertensive and normotensives. J Pak Med Assoc 2008; 58:711-4.

16. Boland A, Cherry M, Dickson R. Doing a systematic review: a student's guide. London: Sage, 2014.

17. Mays N, Pope C, Popay J. Systematically Reviewing Qualitative and Quantitative Evidence to Inform Management and PolicyMaking in the Health Field. J Health Serv Res Policy 2005; 10(Supplement 1):6-20

18. Institute of Medicine. Finding what works in healthcare: standards for systematic review. Washington, DC: The National Academic Press, 2011.

19. Higgins J, Green, S. Cochrane handbook of systematic reviews of interventions. London: John Wiley and Sons Ltd, 2001.

20. Young J, Solomon, M. How to critically appraise an article. National Clinical Practice Gastroenterol Hepatol 2009;6:82-91.

21. Daykin N, Orme J, Evans D, Salmon D, McEachran M, Brain S. The Impact of Participation in Performing Arts on Adolescent Health and Behaviour: A Systematic Review of the Literature. J Health Psychol 2008;13:25164.

22. Moher D, Liberati A, Tetzlaff J, Altman DG, The PRISMA Group. Preferred reporting items for systematic reviews and Meta-Analyses: The PRISMA Statement. PLoS Med 2009;6: e1000097.

23. Khan A, Thaver I. Comparison of tobacco use between urban and rural females. $J$ Coll Physicians Surg Pak 1999;9:11-3.

24. Mahesar H, S, Mahesar, Khand, F, Khand, A,
Seehar G. Effects of smoking on blood pressure of inhabitants of Hyderabad vicinity. Sindh Univ Res Jour 2009;41:25-30.

25. Saleheen D, Hashmi S, Zaidi M, Rasheed A, Murtaza M, Abbas A, Nasim S, Hameed M, Shuja F, Sethi M, Hussain I, Kamran S, Khalid H, Ahmad U, Frossard P, Ishaq M. Evaluation of therapeutic control in a Pakistani population with hypertension. J Eval Clin Pract 2010; 16:1081-4.

26. Shafique K, Mirza S, Mughal, M, Arain Z, Naveed K, Tareen M, Ahmad I. Water-pipe smoking and metabolic syndrome: A population-based study 2012. PLoS One 2014;7:1-6.

27. Tassaduqe K, Ali M, Abdus S, Latif M, Afroze N, Masood S, Umar S. Hypertension in relation to obesity, smoking, stress, family history, age and marital status among human population of Multan, Pakistan. J Med Sci 2004; $4: 30-5$.

28. Dominiak P, Fuchs G, Vontoth S, Grobecker $\mathrm{H}$. Effects of nicotine and its major metabolites on blood pressure in an anesthetized rats. Wien Klin Wochenschr 1985;63:90-92.

29. Green Ms, Jucha E, Luz J. Blood pressure in smokers and nonsmokers: Epidemiological findings. Am Heart J 1986;111:932-40.

30. Okubo Y, Miyamoto T, Suwazono Y, Kobayashi E, Nogawa K. An association between smoking habits and blood pressure in normotensive Japanese men. J Hum Hypertens 2002; 16:91-96.

31. Criqui MH, Mebane I, Wallace RB, Heiss G, Holdbrook MJ. Multivariate correlates of adult blood pressure in nine North American populations: the lipid research clinics prevalence study. Prev Med 1982;11:391-402.

32. Simon LA, Simons J, Jones A. The interactions of body weight, age, cigarette smoking and hormones usage with blood pressure and plasma lipids in Australian community. Aust $N$ Z J Med 1982;14:215-21.

33. Cesaris R, Ranieri G, Filitti V, Bonfantino MV, Andriani A. Cardiovascular effects of cigarette smoking. Cardiol 1992;81:233-7.

34. Aronow WS, Dendinger J, Rokaw SN. Heart rate and carbon monoxide level after smoking high-low and non-nicotine cigarettes. Ann Intern Med 1971;74:697-702.

35. Nishtar S. Prevention of coronary heart disease in South Asia. Lancet 2002;360:1015-8. 